\title{
Analisis Pengendalian Mutu (Quality Control) CPO (Crude Palm Oil) pada PT. XYZ
}

\author{
Dewi Diniaty ${ }^{1}$, Farida Hanum ${ }^{2}$, Muhammad Ihsan Hamdy ${ }^{3}$ \\ 1,2,3 Program Studi Teknik Industri, Fakultas Sains dan Teknologi, UIN Sultan Syarif Kasim Riau \\ Jl. H.R Soebrantas No. 155 KM. 15 Simpang Baru Panam Pekanbaru 28293 \\ Email: dewidiniaty@uin-suska.ac.id,m.ihsanhamdy@uin-suska.ac.id
}

\begin{abstract}
ABSTRAK
PT. XYZ merupakan perusahaan yang bergerak dalam bidang agroindustri kelapa sawit yang terletak di Provinsi Sumatera Utara. Penelitian ini bertujuan untuk menganalisis pengendalian mutu CPO (Crude Palm Oil) pada PT. XYZ. Analisis dilakukan dengan cara mengolah data kadar asam lemak bebas, kadar air, dan kadar kotoran dengan menggunakan alat analisis pengendalian mutu diagram histogram, grafik kendali, dan diagram sebab akibat. Hasil analisis dibandingkan dengan standar pengendalian mutu yang ditetapkan BSN melalui SNI 01-2901-2006. Berdasarkan analisis diagram histogram untuk kadar asam lemak bebas, kadar air, dan kadar kotoran tidak terdapat data yang berada di luar batas. Berdasarkan hasil analisis grafik kendali pengendalian mutu CPO (Crude Palm Oil), jumlah sampel untuk kadar asam lemak bebas, kadar air dan kadar kotoran menurut peta kontrol Xbar dan R tidak terdapat data yang berada diluar batas kendali, setelah melakukan revisi terhadap peta kendali Xbar dan R. Berdasarkan hasil analisis diagram sebab akibat yaitu dilakukan observasi lapangan dan wawancara terhadap lima faktor yang mempengaruhi pengendalian mutu CPO (Crude Palm Oil). Faktor itu sendiri meliputi bahan baku, manusia dan metode kerja.
\end{abstract}

Kata Kunci: Analisis Pengendalian Mutu, Diagram Sebab Akibat, Peta Kendali X dan R.

\section{Pendahuluan}

Kelapa sawit merupakan salah satu komoditi unggulan yang memiliki andil yang signifikan bagi perekonomian Indonesia. Indonesia saai ini merupakan negara penghasil CPO terbesar di dunia. Peluang bisnis pertanian kelapa sawit dan produk turunannya sangatlah menjanjikan untuk pengembangan lahan pertanian dan pengembangan pabrik kelapa sawit. Iklim tropis dan curah hujan yang cukup memungkinkan tanaman kelapa sawit tumbuh dengan baik di wilayah Indonesia.

Proses Produksi dikatakan baik apabila proses tersebut menghasilkan produk yang memenuhi standar yang telah ditetapkan. Namun pada kenyataannya dalam proses produksi masih sering terjadi berbagai penyimpangan dan hambatan yang mengakibatkan produk dianggap cacat. Oleh karena itu pengendalian kualitas sangatlah perlu dilakukan agar perusahaan dapat megoreksi terjadinya kesalahan atau penyimpangan dalam produksinya (Sirine dan Kurniawati, 2017).

Pasokan kelapa sawit yang diolah menjadi CPO bersumber dari kebun kelapa sawit milik PT. XYZ serta pasokan yang bersumber dari petani sawit di daerah tersebut. CPO yang dihasilkan kemudian akan dijual ke perusahaan-perusahaan lain yang ada di daerah sekitar. Kegiatan pengendalian mutu yang dilakukan oleh PT. XYZ untuk menghasilakan produk CPO mengacu pada standar mutu CPO yang ditetapkan oleh pembeli atau pelanggan. Pemerintah sendiri melalui BSN telah menetapkan standarisasi mutu CPO yang dimuat dalam SNI-01-2901-2006 yaitu:

Tabel 1. Standar Nasional Mutu Kelapa Sawit

\begin{tabular}{|c|c|c|}
\hline No & Karakteristik & Keterangan \\
\hline 1 & Kadar asam lemak bebas & $<5,00 \%$ \\
\hline 2 & Kadar air & $<0,50 \%$ \\
\hline 3 & Kadar kotoran & $<0,50 \%$ \\
\hline 4 & Bilangan yodium & $50-55 \mathrm{~g} / 100 \mathrm{~g}$ TBS \\
\hline 5 & Warna CPO (Crude Palm Oil) & Jingga kemerah-merahan \\
\hline
\end{tabular}

(Sumber: SNI, 2006)

PT. XYZ belum menetapkan standarisasi mutu CPO perusahaan. Selama ini standar mutu yang digunakan oleh PT. XYZ mengikuti kontrak kerja yang ditetapkan oleh pembeli mengikuti standar mutu CPO yang ditetapkan oleh BSN (Badan Standar Nasional) melalui SNI-01-2901-2006. Akan tetapi jika mutu CPO yang dihasilkan melebihi standar kadar mutu yang ditetapkan oleh pelanggan tetap maka PT. XYZ akan memasarkannya kepada perusahaan skala kecil atau menengah.

Salah satu cara untuk mengukur mutu produk ialah penerapan quality control dengan peta kontrol (control charts). Fungsi penerapan quality control tersebut adalah untuk melakukan pengendalian terhadap mutu dari input awal berupa penyelesaian bahan baku, proses produksi, sampai kepada proses output barang jadi (finished goods). Dengan adanya penerapan quality control maka perusahaan dapat melakukan efesieni proses produk, khususnya dalam industri pengolahan CPO kelapa sawit. Berdasarkan uraian dari latar belakang di atas, peneliti tertarik untuk mengadakan penelitian lebih lanjut mengenai masalah pengendalian mutu (quality control) dalam hal pengolahan buah sawit yang ada di PT. XYZ. Untuk itu pada penelitian ini peneliti mengambil judul 
"Analisis Pengendalian Mutu (Quality Control) CPO (Crude Palm Oil) pada PT. XYZ".

\section{Metode Penelitian}

Pengendalian kualitas merupakan salah satu teknik yang perlu dilakukan mulai dari sebelum proses produksi berjalan, pada saat proses produksi, hingga proses produksi berakhir dengan menghasilkan produk akhir. Pengendalian kualitas ilakukan agar dapat menghasilkan produk berupa barang atau jasa yang sesuai dengan standar yang diinginkan dan direncanakan, sera memperbaiki kualitas produk yang belum sesuai dengan standar yang telah ditetapkan dan sebisa mungkinmempertahankan kualitas yang sesuai (Supriyadi, 2018).

Tujuan pengendalian kualitas adalah terdapatnya peningkatan kepuasan konsumen, proses produksi dapat dilaksanakan dengan biaya serendah-rendahnya serta selesai sesuai dengan waktu yang telah ditetapkan. Tujuan akhir dari pengendalian kualitas adalah sebagai alat yang efektif dalam pengurangan variabilitas produk (Elmas, 2017).

\section{Histogram}

Histogram menunjukkan cakupan nilai suatu perhitungan dan frekuensi dari setiap nilai yang terjadi. Histogram menunjukkan peristiwa yang sering terjadi dan juga variasi dalam pengukuran (D, 2014).

\section{Peta Kendali}

Peta kendali terbagi 2 yaitu peta kendali untuk data variabel dan peta kendali untuk data atribut. Peta kendali untuk data variabel yaitu peta $X$ dan $R$, Peta $X$ dan $\mathrm{S}$ sedangkan peta kendali untuk data atribut yaitu peta- $P$, peta- $C$, dan peta- $U$ (Besterfield, 1994). Pada Penelitian ini peneliti menggunakan peta kendali $\mathrm{X}$ dan $\mathrm{R}$. Peta kendali $\mathrm{X}_{\mathrm{bar}}$ digunakan untuk proses yang memiliki karakteristik yang bersifat kontinu. Langkahlangkah penentuan peta kendali $\mathrm{X}_{\mathrm{bar}}$ adalah dengan menentukan rentang rata-rata kemudian menetukan batas kontrol serta menggambarkan garis $\mathrm{X}_{\text {bar }}$ dan garis batas kontrol. Peta kendali $\mathrm{R}$ merupakan peta kendali untuk menggambarkan rentang data dari suatu sub grup, yaitu data terbesar dikurangi data terkecil. Langkah-langkah penetuan garis central adalah dengan menentukan rentang rata-rata kemudian menentukan batas kontrol serta menggambarkan garis $\mathrm{R}$ dan garis batas kontrol (D, 2014).

Menghitung X rata-rata dan $\mathrm{R}$ rata-rata (Besterfield, 1994):

$\overline{\overline{\mathrm{X}}}=\frac{\sum_{\mathrm{i}=1}^{\mathrm{g}} \overline{\mathrm{x}}_{\mathrm{i}}}{\mathrm{g}}$

$\overline{\mathrm{R}}=\frac{\sum_{\mathrm{i}=1}^{\mathrm{g}} \mathrm{R}_{\mathrm{i}}}{\mathrm{g}}$

Dimana:
$\overline{\overline{\mathrm{X}}}$ : jumlah rata-rata dari nilai rata-rata subgrup

$\overline{\mathrm{x}}_{\mathrm{i}}$ : nilai rata-rata subgrup ke-i

$\overline{\mathrm{R}}$ : jumlah rata-rata rentang grup

$\mathrm{R}_{\mathrm{i}}$ : nilai rentang subgrup $\mathrm{ke}-\mathrm{i}$

$\mathrm{g}$ : jumlah subgroup

Menentukan batas kontrol untuk pembuatan peta kendali X dan R (D, 2014):

Batas kontrol peta $\mathrm{X}$ :

Batas kontrol atas (BKA) $=\overline{\overline{\mathrm{x}}}+\mathrm{A}_{2} \mathrm{R}$

Batas kontrol bawah $(\mathrm{BKB})=\overline{\overline{\mathrm{X}}}-\mathrm{A}_{2} \mathrm{R}$

Batas kontrol peta $\mathrm{R}$ :

Batas kontrol atas $(\mathrm{BKA})=\mathrm{D}_{4} \cdot R$

Batas kontrol bawah $(\mathrm{BKB})=\mathrm{D}_{3} \cdot R$

Dimana:

BKA $=$ Batas Kontrol Atas

$\mathrm{BKB}=$ Batas Kontrol Bawah

$\mathrm{A}_{2} \quad=$ Nilai Koefisien

$D_{4}, D_{3}=$ Nilai Koefisien

$\mathrm{R} \quad=$ Selisih Harga $\mathrm{X}_{\text {maks }}$ dan $\mathrm{X}_{\text {min }}$

Menghitung X rata-rata dan R rata-rata revisi (Besterfield, 1994):

$\overline{\bar{X}}_{\text {new }}=\frac{\bar{X}-\bar{X} d}{g-g d}$

$\overline{\bar{R}}_{\text {new }}=\frac{\overline{\mathrm{R}}-\overline{\mathrm{R}} \mathrm{d}}{\mathrm{g}-\mathrm{gd}}$

$\sigma_{0} \quad=\frac{\mathrm{R}_{0}}{\mathrm{~d}_{2}}$

Menentukan batas kontrol untuk pembuatan peta kendali X dan R revisi (Besterfield, 1994):

Batas kontrol peta $\mathrm{X}$ :

Batas kontrol atas (BKA) $=\overline{\mathrm{X}}_{0}+\mathrm{A} \sigma_{0}$

Batas kontrol bawah $(\mathrm{BKB})=\overline{\mathrm{X}}_{0}-\mathrm{A} \sigma_{0}$

Batas kontrol peta R:

Batas kontrol atas $(\mathrm{BKA})=\mathrm{D}_{2} \cdot \sigma_{0}$

Batas kontrol bawah $(\mathrm{BKB})=\mathrm{D}_{1} \cdot \sigma_{0}$

Dimana:

$\mathrm{S}_{\mathrm{d}}=$ Sampel deviasi standar subgrup yang dibuang

$\mathrm{D}_{2}=$ Lihat dari Tabel $\mathrm{C}$

A, $D_{2}, D_{1}=$ Nilai Koefisien (lihat tabel F)

\section{Diagram Sebab Akibat}

Diagram ini berguna untuk menganalisa dan menemukan faktor-faktor yang berpengaruh secara signifikan dalam menentukan karakteristik kualitas output kerja serta untuk mencari penyebab-penyebab yang sesungguhnya dari suatu masalah. Untuk mencari faktorfaktor penyebab terjadinya penyimpangan kualitas hasil kerja, maka orang kan selalu mendapatkan bahwa ada 5 
faktor penyebab utama yang signifikan yang perlu diperhatikan, yaitu (Wignjosoebroto, 2003).

1. Manusia (man).

2. Metode Kerja (work method).

3. Mesin atau peralatan kerja lainnya (machinelequipment).

4. Bahan-bahan baku (raw materials).

5. Lingkungn Kerja (work environment).

Diagram ini disebut juga diagram tlang ikan (fishbone chart) dan berguna untuk memperlihatkan faktor-faktor utama yang berpengaruh padakualitas dan mempunyai akibat pada masalah yang kita pelajari, selain itu kita juga dapat melihat faktor-faktor yang lebih terperinci yang berpengaruh dan mempunyai akibat pada faktor utama tersebut yang dapat kita lihat pada panahpanah yang berbentuk tulang ikan pada diagram fisbhone tersebut.

\section{Hasil dan Pembahasan}

\section{Histogram}

Histogram Kadar Asam Lemak Bebas (ALB)

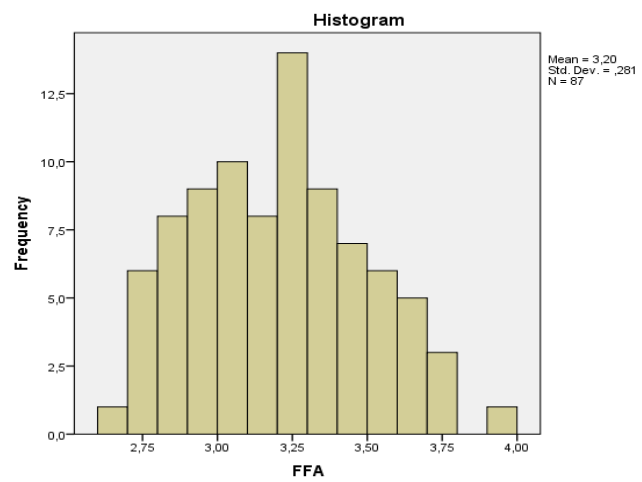

Gambar 1. Hasil Uji Kadar Asam Lemak Bebas

Berdasarkan hasil histogram untuk kadar asam lemak bebas, maka dapat dilihat bahwa rata-rata kadar asam lemak bebas adalah 3,2\%, dan tidak terdapat data yang berada diluar batas normal berdasarkan standarisasi yang ditetapkan oleh BSN yaitu kadar asam lemak bebas maksimum 5\%.

\section{Histogram Kadar Air (Volatile Metre)}

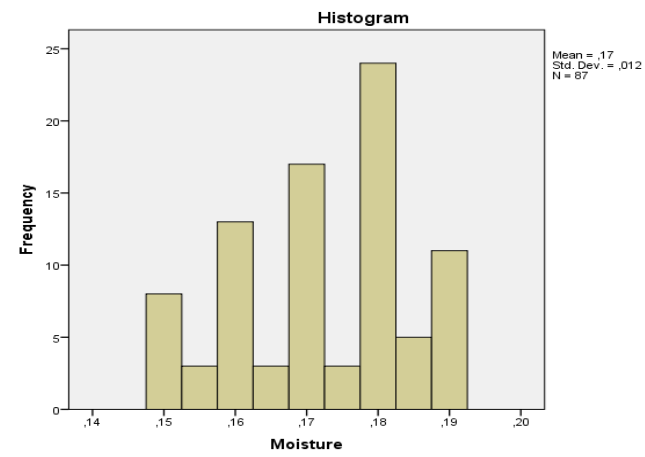

Gambar 2. Hasil Uji Kadar Air

Berdasarkan hasil histogram untuk kadar air, maka dapat dilihat bahwa rata-rata kadar air adalah $0,17 \%$, dan tidak terdapat data yang berada diluar batas normal berdasarkan standarisasi yang ditetapkan oleh BSN yaitu kadar air maksimum $0,5 \%$.

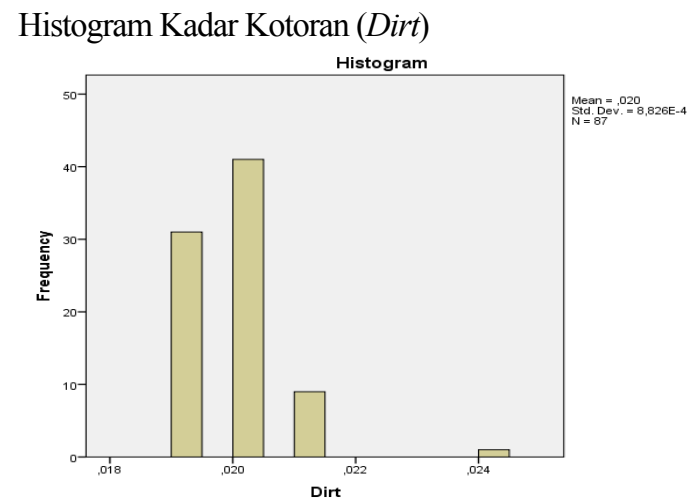

Gambar 3. Hasil Uji Kadar Kotoran

Berdasarkan hasil histogram untuk kadar kotoran, maka dapat dilihat bahwa rata-rata kadar kotoran adalah $0,020 \%$, dan tidak terdapat data yang berada diluar batas normal berdasarkan standarisasi yang ditetapkan oleh BSN yaitu kadar kotoran maksimum $0,5 \%$.

\section{Analisis Grafik Kendali (SPC)}

Analisis grafik kendali digunakan untuk melakukan pengendalian kinerja proses dengan menggunakan metode statistik. Pada grafik kendali terdapat garis batas kendai atas (UCL) serta garis batas kendali bawah (LCL), kedua garis berfungsi untuk menentukan batas kendali kandungan mutu $\mathrm{CPO}$ dalam perhitungan statistik. Berikut tahapan pembuatan grafik kendali $\overline{\mathrm{X}}$ dan $\mathrm{R}$ untuk Kadar Asam Lemak Bebas, Kadar Air dan Kadar Kotoran:

Peta $\bar{X}$ dan R untuk Kadar Asam Lemak Bebas

1. Perhitungan Peta Kendali $\mathrm{X}_{\text {bar }}$ Kadar Asam Lemak Bebas

$$
\begin{aligned}
\mathrm{UCL}_{\overline{\mathrm{X}}} & =\overline{\overline{\mathrm{X}}}+\mathrm{A}_{2} \mathrm{R} \\
& =2,99+1,02 \cdot 0.43 \\
& =2,99+0.4386 \\
& =3,43 \% \\
& =\overline{\overline{\mathrm{x}}}-\mathrm{A}_{2} \mathrm{R} \\
\mathrm{LCL}_{\overline{\mathrm{X}}} & 2,99-1,02.0 .43 \\
& =2,99-0.4386 \\
& =2,55 \%
\end{aligned}
$$

Perhitungan Peta Kendali R Kadar Asam Lemak Bebas

$$
\begin{aligned}
\mathrm{UCL}_{\overline{\mathrm{R}}} & =\mathrm{D}_{4} \cdot \bar{R} \\
& =2,57 \cdot 0.43 \\
& =1,10 \% \\
\mathrm{LCL}_{\overline{\mathrm{R}}} & =\mathrm{D}_{3} \cdot \bar{R} \\
& =0.0 .43 \\
& =0 \%
\end{aligned}
$$




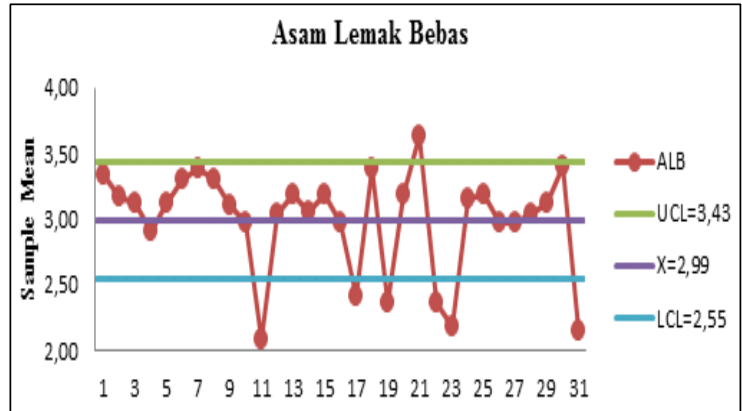

Gambar 4. Grafik Kendali $\mathrm{X}_{\text {bar }}$ Asam Lemak Bebas

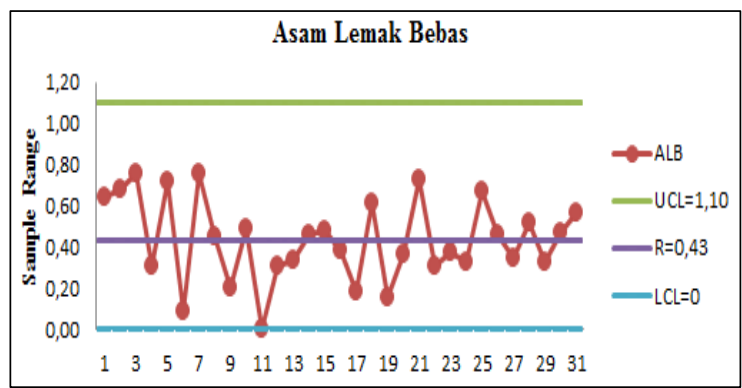

Gambar 5. Grafik Kendali $\mathrm{R}_{\text {bar }}$ Asam Lemak Bebas

Dari peta kendali $\mathrm{X}_{\text {bar }}$ dan $\mathrm{R}$ diatas terdapat data yang berada diluar batas control, yaitu pada data ke 11, $17,19,21,22,23$ dan 31 pada peta kendali $X_{\text {bar }}$ dan harus dilakukan revisi. Sedangkan untuk peta kendali $\mathrm{R}$ tidak terdapat data yang berada diluar batas control. Adapun perhitungan revisi peta kendali $X_{\text {bar }}$ adalah sebagai berikut:

$$
\begin{aligned}
\overline{\bar{X}}_{\text {new }}= & \frac{\overline{\mathrm{X}}-\overline{\mathrm{X}} \mathrm{d}}{\mathrm{g}-\mathrm{gd}} \\
= & \frac{92,78-2,09-2,41-2,36-3,62-2,36-2,18-3,15}{31-7} \\
= & \frac{75,58}{24} \\
= & 3,15 \% \\
\overline{\mathrm{R}}_{\text {new }}= & 0,43 \% \\
\sigma_{0} & \frac{\mathrm{R}_{0}}{\mathrm{~d}_{2}} \\
= & \frac{0,43}{1,693}=0,25 \% \\
\mathrm{UCL}_{\overline{\mathrm{X}}}= & \bar{X}_{0}+\mathrm{A} \sigma_{0} \\
= & 3,15+(1,23)(0,25) \\
= & 3,15+0,3075 \\
& =3,46 \% \\
\mathrm{LCL}_{\overline{\mathrm{X}}}= & \bar{X}_{0}-\mathrm{A} \sigma_{0} \\
= & 3,15-(1,23)(0,25) \\
= & 3,15-0,3075 \\
& =2,84 \% \\
&
\end{aligned}
$$

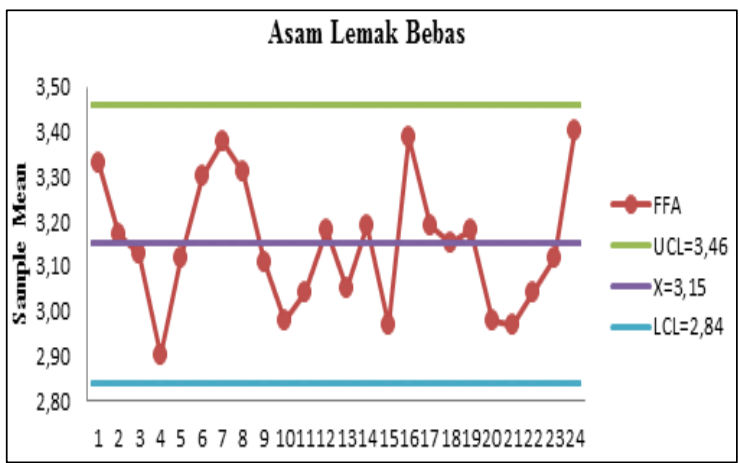

Gambar 6. Revisi Peta Kendali $X_{\text {bar }}$ Asam Lemak Bebas

2. Perhitungan Peta Kendali $X_{\text {bar }}$ Kadar Air

$$
\begin{aligned}
\mathrm{UCL}_{\overline{\mathrm{X}}} & =\overline{\mathrm{X}}+\mathrm{A}_{2} \mathrm{R} \\
& =0,16+1,02.0 .02 \\
& =0,16+0.0204 \\
& =0,18 \% \\
\mathrm{LCL}_{\overline{\mathrm{X}}} & =\overline{\overline{\mathrm{X}}}-\mathrm{A}_{2} \mathrm{R} \\
& =0,16-1,02.0 .02 \\
& =0,16-0.0204 \\
& =0,13 \%
\end{aligned}
$$

Perhitungan Peta Kendali R Kadar Air

$$
\begin{aligned}
\mathrm{UCL}_{\overline{\mathrm{R}}} & =\mathrm{D}_{4} \cdot \bar{R} \\
& =2,57 \cdot 0.02 \\
& =0,05 \% \\
\mathrm{LCL}_{\overline{\mathrm{R}}} & \mathrm{D}_{3} \cdot \bar{R} \\
& =0.0 .02 \\
& =0 \%
\end{aligned}
$$

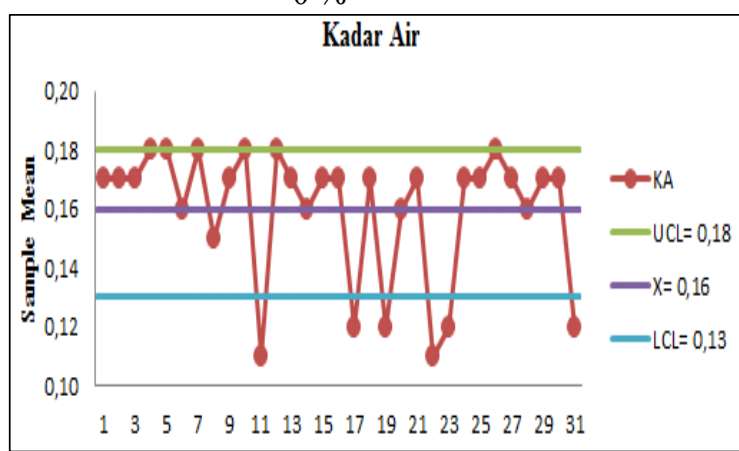

Gambar 7. Grafik Kendali $X_{\text {bar }}$ Kadar Air

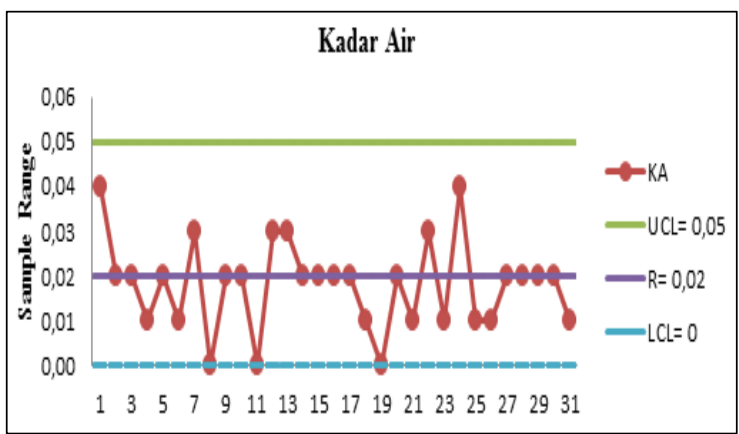

Gambar 8. Grafik Kendali $\mathrm{R}_{\text {bar }}$ Kadar Air

Dari peta kendali $\mathrm{X}_{\mathrm{bar}}$ dan $\mathrm{R}$ diatas terdapat data yang berada diluar batas control, yaitu pada data ke 11, 17, 19, 22, 23 dan 31 pada peta kendali $X_{\text {bar }}$ dan harus 
dilakukan revisi. Adapun perhitungan revisi peta kendali $\mathrm{X}_{\text {bar }}$ adalah sebagai berikut:

$$
\begin{aligned}
\overline{\bar{X}}_{\text {new }}= & \frac{\overline{\mathrm{X}}-\overline{\mathrm{X}} \mathrm{d}}{\mathrm{g}-\mathrm{gd}} \\
& =\frac{4,97-0,11-0,12-0,12-0,11-0,12-0,12}{31-6} \\
& =\frac{4,26}{25} \\
& =0,17 \% \\
\overline{\overline{\mathrm{R}}}_{\text {new }}= & 0,02 \% \\
\sigma_{0} & \frac{\mathrm{R}_{0}}{\mathrm{~d}_{2}} \\
& =\frac{0,02}{1,693}=0,01 \% \\
\mathrm{UCL}_{\overline{\mathrm{X}}}= & \bar{X}_{0}+\mathrm{A} \sigma_{0} \\
& =0,17+(1,23)(0,01) \\
& =0,17+0,0123=0,18 \% \\
\mathrm{LCL}_{\overline{\mathrm{X}}}= & \bar{X}_{0}-\mathrm{A} \sigma_{0} \\
= & 0,17-(1,23)(0,01) \\
= & 0,17-0,0123 \\
& =0,15 \%
\end{aligned}
$$

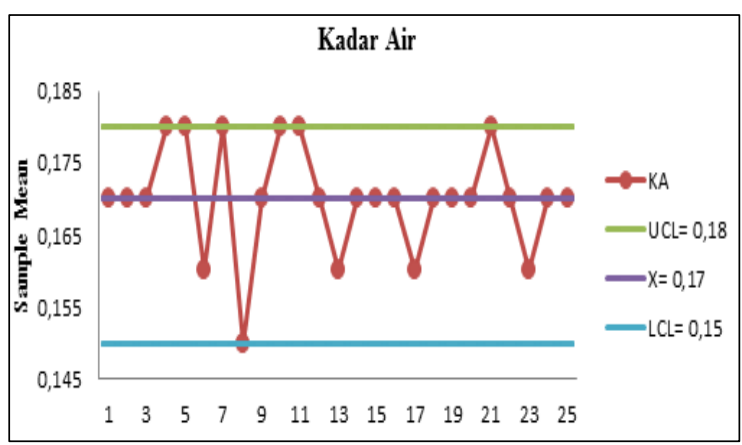

Gambar 9. Revisi Peta Kendali $\mathrm{X}_{\text {bar }}$ Kadar Air

3. Perhitungan Peta Kendali $X_{\text {bar }}$ Kadar Kotoran

$$
\begin{aligned}
\mathrm{UCL}_{\overline{\mathrm{X}}} & =\overline{\overline{\mathrm{x}}}+\mathrm{A}_{2} \mathrm{R} \\
& =0,018+1,02.0 .001 \\
& =0,018+0.00102 \\
& =0,019 \% \\
& =\overline{\overline{\mathrm{x}}}-\mathrm{A}_{2} \mathrm{R} \\
& =0,018-1,02.0 .001 \\
& =0,018-0.00102 \\
& =0,017 \%
\end{aligned}
$$

Perhitungan Peta Kendali R Kadar Kotoran

$$
\begin{aligned}
\mathrm{UCL}_{\overline{\mathrm{R}}} & =\mathrm{D}_{4} \cdot \bar{R} \\
& =2,57 \cdot 0.001 \\
& =0,003 \% \\
\mathrm{LCL}_{\overline{\mathrm{R}}} & =\mathrm{D}_{3} \cdot \bar{R} \\
& =0.0 .001
\end{aligned}
$$

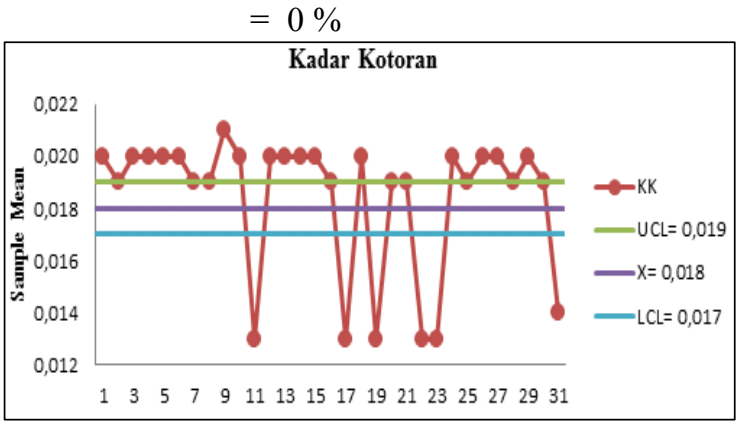

Gambar 10. Grafik Kendali $X_{\text {bar }}$ Kadar Kotoran

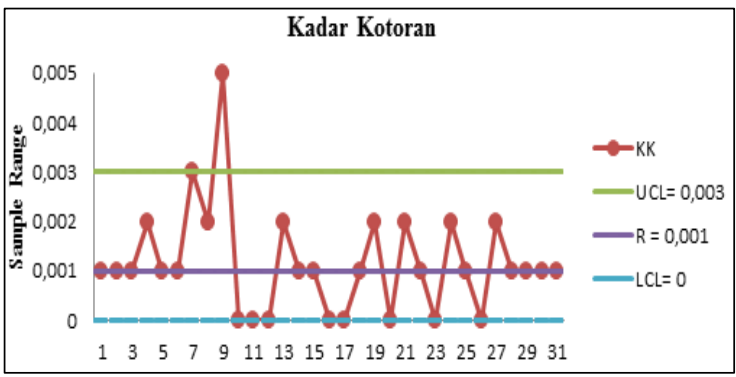

Gambar 11. Grafik Kendali $\mathrm{R}_{\text {bar }}$ Kadar Kotoran

Dari peta kendali $\mathrm{X}_{\text {bar }}$ dan $\mathrm{R}$ diatas terdapat data yang berada diluar batas control yaitu pada data ke 1,2 , $3,4,5,6,9,10,11,12,13,14,15,17,18,19,22,23,24$, 26, 27, 29 dan 31 pada peta kendali $\mathrm{X}_{\text {bar }}$ dan untuk peta kendali $\mathrm{R}$ terdapat pula data yang berada diluar batas control yaitu pada data ke 9, maka harus dilakukan revisi pada data yang berada diluar batas control. Adapun perhitungan revisi peta kendali $\mathrm{X}_{\text {bar }}$ dan $\mathrm{R}$ adalah sebagai berikut:

$$
\begin{aligned}
\overline{\bar{X}}_{\text {new }} & =\frac{\bar{X}-\bar{X} d}{g-g d} \\
& =\frac{0,571-0,020-0,020-0,021-\ldots \ldots-0,014}{31-22} \\
& =\frac{0,173}{9}=0,019 \%
\end{aligned}
$$$$
\overline{\bar{R}}_{\text {new }}=\frac{\overline{\mathrm{R}}-\overline{\mathrm{R}} \mathrm{d}}{\mathrm{g}-\mathrm{gd}}
$$$$
=\frac{0,036-0,005}{31-1}
$$$$
=\frac{0,031}{29}
$$$$
=0,001 \%
$$$$
\sigma_{0}=\frac{\mathrm{R}_{0}}{\mathrm{~d}_{2}}
$$

$$
=\frac{0,001}{1,693}=0,0006 \%
$$

$$
\begin{aligned}
\mathrm{UCL}_{\overline{\mathrm{X}}}= & \bar{X}_{0}+\mathrm{A} \sigma_{0} \\
& =0,019+(1,23)(0,0006) \\
& =0,019+0,0073
\end{aligned}
$$




$$
\begin{aligned}
& =0,026 \% \\
\mathrm{LCL}_{\overline{\mathrm{X}}}= & \bar{X}_{0}-\mathrm{A} \sigma_{0} \\
= & 0,019-(1,23)(0,0006) \\
= & 0,019-0,0073 \\
& =0,011 \% \\
\mathrm{UCL}_{\overline{\mathrm{R}}} & =\mathrm{D}_{2} \cdot \sigma_{0} \\
& =4,36 \cdot 0.0006 \\
& =0,003 \% \\
& =\mathrm{D}_{1} \cdot \sigma_{0} \\
& =0.0 .0006 \\
\mathrm{LCL}_{\overline{\mathrm{R}}} & =0 \%
\end{aligned}
$$

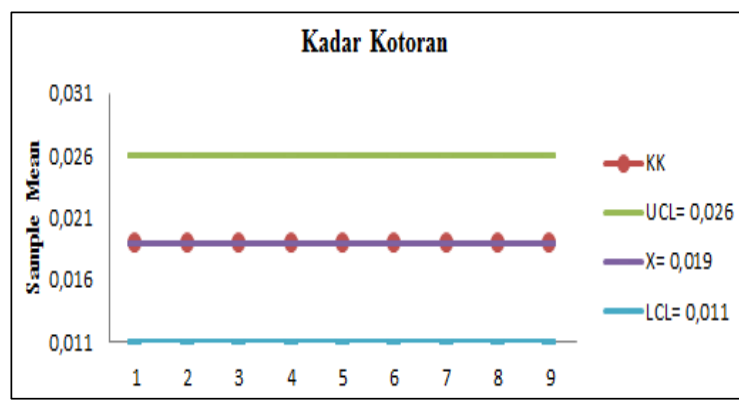

Gambar 12. Revisi Peta Kendali $X_{\text {bar }}$ Kadar Kotoran

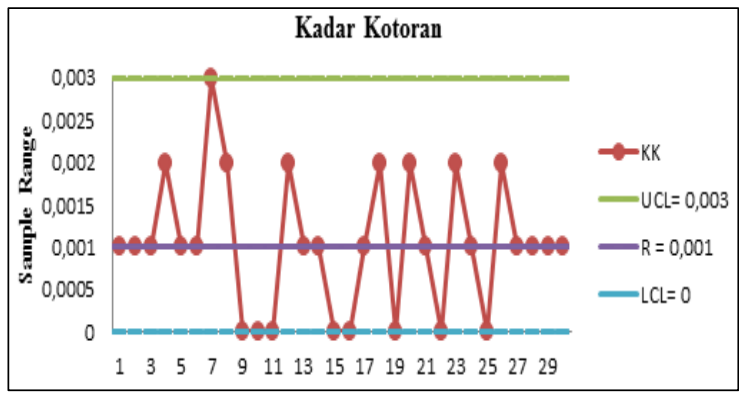

Gambar 13. Revisi Peta Kendali $\mathrm{R}_{\text {bar }}$ Kadar Kotoran

\section{Diagram Sebab Akibat \\ Bahan Baku}

Bahan baku yang digunakan oleh PT. XYZ adalah TBS yang berasal dari kebun sendiri dan TBS dari kebun luar. TBS yang dikirim dari kebun terkadang terdapat beberapa kualitas kematangan kurang baik. Hal ini tentunya akan mempengaruhi tingkat keasaman atau FFA yang terkandung didalam buah.

\section{Lingkungan Kerja}

PT. XYZ memiliki luas area pabrik 10 ha yang didalamnya terdapat bangunan-bangunan pabrik yang terdiri dari pos pengamanan yang berada di gerbang masuk pabrik, dan juga terdapat jembatan timbang yang digunakan untuk menimbang kendaraan yang membawa bahan baku TBS, kemudian kantor dan laboratorium yang digunakan untuk kegiatan administrasi dan pengujian kadar CPO. Pada penempatan penumpukan bahan baku atau yang disebut Loading Ramp yang dimiliki oleh PT. XYZ tidak memiliki atap, dan jika hujan tempat penumpukan (loading ramp) akan berlumpur sehingga TBS yang akan diolah menjadi kotor, akibat terkena lumpur dan kadar air pada buahnya akan bertambah karena terkena air hujan. Apabila proses produksi berjalan, maka lingkungan kerja akan terdapat sisa sampah seperti brondolan yang jatuh dan terdapat lantai yang licin. Tentunya akan mempengaruhi kualitas buah yang berada didekat area kotor tersebut.

\section{Manusia}

Karyawan yang memiliki peran yang sangat penting terhadap hasil mutu produk yang dihasilkan oleh PT. XYZ. Terutama karyawan produksi yang bertugas sebagai operator harus berkonsentrasi penuh dalam mengendalikan mesin dan peralatan yang digunakan dalam proses pengolahan TBS yang akan menjadi Crude Palm Oil. Tingkat kedisiplinan dan ketelitian ini sangat penting untuk dimiliki karyawan didalam pabrik maupun di laboratorium. Terutama didalam laboratorium ketelitian dibutuhkan untuk menguji tingkat asam lemak yang terkandung dalam CPO yang nantinya akan menentukan keberhasilan produk yang dihasilkan oleh PT. XYZ.

\section{Mesin}

Perawatan mesin yang dilakukan pada PT. XYZ sudah baik walaupun terkadang ada kerusakan disalah satu mesin produksi. Sehingga hal ini tentunya akan mengakibatkan kinerja perusahaan terhambat dalam proses pengolahan TBS (Tandan Buah Segar). Mesin yang digunakan dan beroperasi setiap hari tentunya harus melakukan perawatan yang rutin sesuai dengan penggunaan dan penjadwalan yang baik tentunya untuk mendapatkan hasil yang baik pula.

\section{Metode Kerja}

Pada metode kerja terdapat beberapa tahapan yang dilakukan, intinya ialah merupakan proses perebusan TBS yang selanjutnya akan menghasilkan CPO. Kualitas metode kerja juga menentukan hasil CPO yang diproduksi. Proses ini dipengaruhi oleh bahan baku TBS, setingan mesin, serta penampungan sementara hasil produksi. Bahan baku TBS merupakan hal yang sangat penting harus diperhatikan oleh karyawan bagian penyortiran, karena akan memberikan efek yang sangat besar pada proses selanjutnya. Kemudian setingan mesin merupakan hal yang penting yang harus diperhatikan oleh karyawan produksi, karena sangat berpengaruh terhadap tinggi rendahnya tingkat FFA yang akan dihasilkan oleh CPO. Apabila tingkat FFA tinggi maka dengan segera pihak laboratorium akan melaporkan atau menegur kepada pihak produksi untuk mengecek atau merubah setingan mesin agar tingkat FFA sesuai dengan target perusahaan.

Dari analisis diagram sebab akibat dapat diketahui bahwa faktor penyebab terjadinya penyimpangan kualitas CPO adalah faktor bahan baku, metode kerja, manusia, mesin dan lingkungan kerja. Dimana faktor yang secara umum sering terjadi pada PT. XYZ adalah bahan baku, metode kerja dan manusia. Maka dapat digambarkan 
akar penyebab dari tinggi rendahnya asam lemak bebas, kadar air dan kadar kotoran seperti pada gambar dibawah ini:

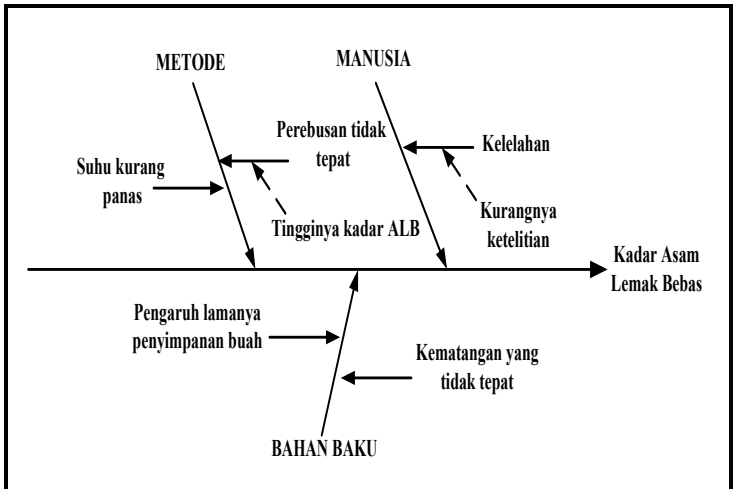

Gambar 14. Diagram Sebab Akibat Kadar Asam Lemak Bebas

Berdasarkan gambar 15 diketahui penyebab tinggi rendahnya kadar asam lemak bebas yaitu bahan baku, manusia dan metode. Adapun penjelasan ketiga faktor adalah sebagai berikut:

1. Bahan Baku

Penyebab tingginya kadar asam lemak bebas disebabkan oleh kematangan buah yang tidak tepat, buah yang terdapat pada satu tandan buah kelapa sawit tidak akan matang secara serempak. Buah yang berada dilapisan luar biasanya lebih matang jika dibandingkan dengan buah yang berada pada bagian yang lebih dalam. Hal ini mengakibatkan perbedaan persentase minyak yang terdapat pada setiap buah yang berada dalam satu tandan. Selain itu perebusan tidak tepat juga mempengaruhi tingginya kadar asam lemak bebas dan secara alami asam lemak bebas akan terbentuk seiring dengan lamanya penyimpanan bahan baku kelapa swit.

2. Manusia

Dalam melakukan penyortiran buah terkadang para pekerja tidak melakukan penyortiran dengan baik, disebabkan oleh pekerja yang kelelahan sehingga kurangnya ketelitian dalam melakukan penyortiran buah, seperti buah mentah, buah pasir ataupun buah yang sudah memberondol.

3. Metode

Sebab akibat pada metode kerja bisa terjadi pada pengaturan mesin seperti temperatur suhu pada saat perebusan hal ini harus diperhatikan oleh karyawan produksi, karena akan berakibat terhadap kualitas CPO yang dihasilkan.

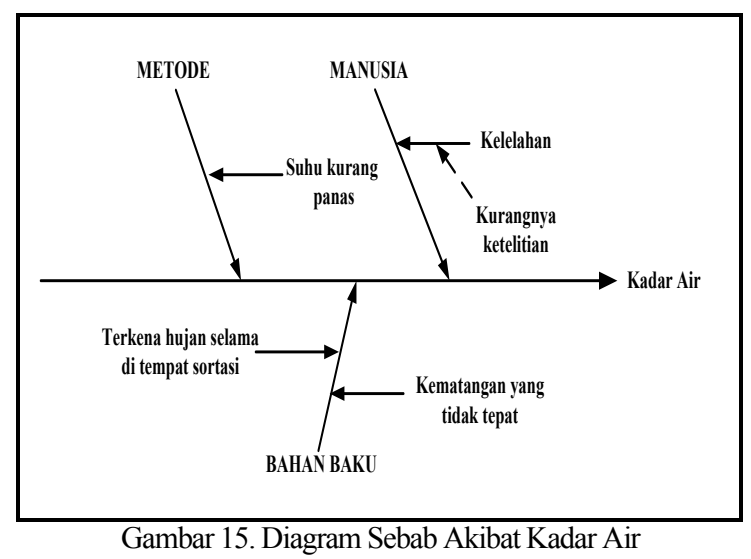

Berdasarkan gambar 16 diketahui penyebab tinggi rendahnya kadar air yaitu bahan baku, manusia dan metode. Adapun penjelasan ketiga faktor adalah sebagai berikut:

1. Bahan Baku

Bahan baku yang terkenah hujan selama ditempat sortasi bisa meningkatkan kadar air pada bahan baku tinggi dan kadar minyak pada buah sawit akan berkurang, selain itu faktor kematangan buah sawit yang tidak tepat juga mempengaruhi tingkat kadar air pada buah tersebut karena buah yang terlalu matang akan mengandung air yang lebih banyak.

2. Manusia

Dalam melakukan penyortiran buah terkadang para pekerja tidak melakukan penyortiran dengan baik yang disebabkan oleh pekerja yang kelelahan, sehingga kurangnya ketelitian dalam melakukan penyortiran buah.

3. Metode

Sebab akibat pada metode kerja bisa terjadi pada pengaturan mesin seperti temperatur suhu pada saat perebusan hal ini harus diperhatikan oleh karyawan produksi, karena akan berakibat terhadap kualitas CPO yang dihasilkan.

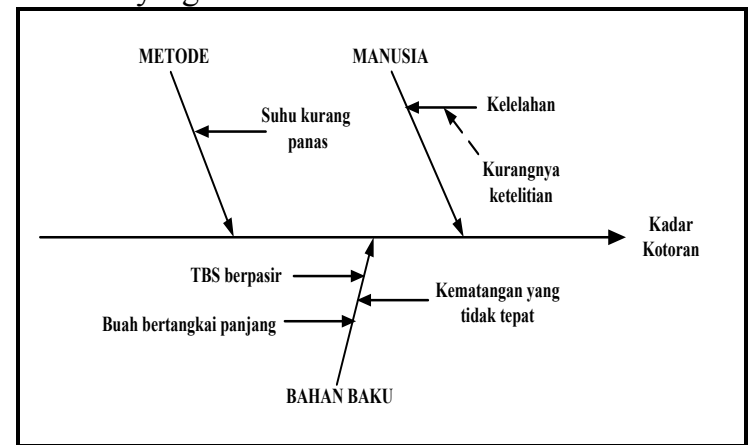

Gambar 16. Diagram Sebab Akibat Kadar Kotoran

Berdasarkan gambar 17 diketahui penyebab tinggi rendahnya kadar kotoran yaitu bahan baku, manusia dan metode. Adapun penjelasan ketiga faktor adalah sebagai berikut:

1. Bahan Baku 
Kadar pengotor seperti pasir disebut sebagai bahanbahan asing yang tidak larut dalam minyak. Pengotor yang tidak terlarut dinyatakan sebagai persen zat pengotor terhadap minyak. Pada umumnya penyaringan hasil minyak sawit dilakukan dalam rangkaian proses pengendapan, dimana dalam proses tersebut kotoran-kotoran atau serabut yang berukuran kecil tidak dapat disaring.

2. Manusia

Selain dari faktor diatas manusia juga memegang peranan penting dalam menghasilkan CPO yang baik. Sebab akibat yang sering terjadi seperti faktor operator yang kurang teliti yang disebabkan oleh kelelahan para karyawan yang bekerja.

3. Metode

Sebab akibat pada metode kerja bisa terjadi pada pengaturan mesin seperti temperatur suhu pada saat perebusan hal ini harus diperhatikan oleh karyawan produksi, karena akan berakibat terhadap kualitas CPO yang dihasilkan.

\section{Kesimpulan}

Berdasarkan hasil pengolahan data dapat disimpulkan bahwa:

1. Standar proses pengendalian mutu yang dilakukan PT. XYZ sebenarnya sudah baik, akan tetapi dalam penerapannya terdapat beberapa penyimpangan yang terjadi saat pelaksanaannya. Adapun proses pengendalian mutu CPO yang dilakukan PT. XYZ dimulai dari proses timbang, stasiun penerimaan buah, stasiun perebusan (sterilizer), stasiun threser, stasiun press, dan stasiun pemurnian.

2. Tingkat mutu CPO yang dihasilkan PT. XYZ sudah memenuhi standar yang ditetapkan oleh Badan Standarisasi Nasional, dimana tingkt mutu CPO pada PT. XYZ yaitu untuk kadar asam lemak bebas sebesar 3,2\%, kadar air sebesar $0,17 \%$, dan kadar kotoran sebesar $0,020 \%$.

berikut:

Adapun saran yang dapat diajukan adalah sebagai

1. Perusahaan sebaiknya lebih teliti memberikan sanksi bagi pemasok yang membawa buah mentah atau yang terlalu matang pada bahan baku (TBS), seperti mendapatkan potongan pembayaran buah sawit atau buah dikembalikan.

2. Area penerimaan buah (loading ramp) pada perusahaan sebaiknya dibuatkan atap agar buah yang disimpan sementara sebelum diolah tidak terkena panas berlebih dan hujan.

\section{Daftar Pustaka}

[1] Abdullah, M. A., Aplikasi Peta Kendali Statistik dalam Mengontrol Hasil Produksi Suatu Perusahaan. Jurnal SAINTIFIK, 1(1), 2015, pp.513.
[2] Amrina, E., dan Nofriani, F., Analisis Ketidaksesuaian Produk Air Minum dalam Kemasan di PT. Amanah Insanillahia. Jurnal Optimasi Sistem Industri, 14(1), 2015, pp.85-101.

[3] Badan Standarisasi Nasional., SNI Crude Palm Oil, Jakarta. 2006.

[4] Besterfield, D. H., Quality Control Fourt Edition. $4^{\text {th }}$ Edition Englewood Cliffs Prentice-Hall International Inc. 1994.

[5] D, M. F. W., Analisis Pengendalan Mutu (Quality Control) CPO (Crude Palm Oil) pada PT. Buana Wira Subur Sakti Kabupaten Paser. Ejournal Ilmu Administrasi, 2(2), 2014, pp.245-259.

[6] Elmas, M. S. H., Pengendalian Kualitas dengan Menggunakan Metode Statistical Quality Control (SQC) untuk Meminimumkan Produk Gagal pada Toko Roti Barokah Bakery. Jurnal Penelitian Ilmu Ekonomi WIGA, 7(1), 2017, pp.15-22.

[7] Sirine, H., dan Elisabeth, P. K., Pengendalian Kualitas Menggunakan Metode Six Sigma (Studi Kasus pada PT. Diras Concept Sukoharjo). AJIE Asian Journal of Innovationand Entrepreneurship, 2(3), 2017, pp.254-290.

[8] Suadi, A., et al., Analisa Pengolahan Kelapa Sawit dengan Kapasitas Olah 30 Ton/Jam di PT. Bio Nusantara Teknologi. Jurnal Program Studi Teknik Mesin, Fakultas Teknik, Universitas Bengkulu, 2(17), 2016, pp.12-19.

[9] Supriyadi, E., Analisis Pengendalian Kualitas Produk dengan Statistical Proces Control (SPC) di PT. Surya Toto Indonesia, Tbk. JITMI, 1(1), 2018, pp.63-73.

[10] Setiawan, L., dan Ida, M. A., Analisis Pengendalian Proses Produksi dengan Metode Statistical Quality Control pada PT. Estwind Mandiri Semarang. Jurnal Ekonomi Manajemen dan Akutansi, 2018, pp.16-28.

[11] Wignjosoebroto, S., Pengantar Teknik dan Manajemen Industri. Guna Widya, Jakarta. 2003. 